\title{
Developing a novel hybrid model for prediction of drought and stress-tolerant indices in teosinte introgressed maize lines using artificial intelligence techniques
}

Vijay Kumar Singh 1, Amarjeet Kumar 2, Bhagwat Saran 3, Nadhir Al-Ansari 4, Vinay Pratap Singh 5, Sneha Adhikari ${ }^{6}$, Anjali Joshi ${ }^{7}$, Narendra Kumar Singh ${ }^{8}$ and Dinesh Kumar Vishwakarma ${ }^{9, *}$

1 Faculty of Agriculture Science and Technology, Mahatma Gandhi Kashi Vidhyapith, Chetganj, Varanasi, Uttar Pradesh 221002, India; vijaysinghswce@gmail.com (V.K.S.)

2 Department of Genetics and Plant Breeding, MTTC \& VTC, Central Agricultural University Selesih, Imphal, Manipur 795004, India; amarjeetgpb@gmail.com (A.K.)

3 Department of Soil and Water Conservation Engineering, College of Technology, G. B. Pant University of Agriculture and Technology, Pantnagar, Uttarakhand 263145, India; saran.bhagwat007@gmail.com (B.S.)

4 Civil, Environmental and Natural Resources Engineering, Lulea University of Technology, 97187 Lulea, Sweden; ir.alansari@ltu.se, https://orcid.org/0000-0002-6790-2653 (N.A.-A.)

5 Department of Plant Physiology, College of Agriculture - Ganj Basoda, Vidisha, Madhya Pradesh 464221, India; drvpsingh10@gmail.com (V.P.S.)

6 ICAR- Regional Station, Indian Institute of Wheat and Barley Research, Regional Station Flowerdale, Shimla, Himachal Pradesh 171002, India; snehaadhikari24@gmail.com (S.A.)

7 Genetics and Tree Improvement Division, Arid Forest Research Institute, Jodhpur, Rajasthan 342005, India anjali99aj@gmail.com (A.J.)

8 Department of Genetics and Plant Breeding, G. B. Pant University of Agriculture and Technology, Pantnagar, Uttarakhand 263145, India; narendraksingh2@gmail.com (N.K.S.)

9 Department of Irrigation and Drainage Engineering, College of Technology, G. B. Pant University of Agriculture and Technology, Pantnagar, Uttarakhand 263145, India; dinesh.vishwakarma4820@gmail.com, https://orcid.org/0000-0002-2421-6995 (D.K.V.)

* Correspondence: dinesh.vishwakarma4820@gmail.com (D.K.V.); Tel.: +91 9670791406

\begin{abstract}
Maize (Zea mays subsp. mays) is the staple food crop in the world. In this study, multilayer perceptron (MLP), support vector machine (SVM), genetic algorithm-based multi-layer perceptron (MLP-GA), and genetic algorithm-based support vector machine (SVM-GA) hybrid artificial intelligence algorithms were used for the prediction of drought tolerance and stress tolerance indices in teosinte maize lines. Correspondingly, the gamma test technique was applied to determine efficient input and output vectors. The potential of developed models was evaluated based on statistical indices and graphical representation. Results of gamma test based on the least value of gamma and standard error indices show that day of anthesis (DOA), day of silking (DOS), yield index (YI), and gross yield per plant (GYP) information vector arrangements were determined as efficient information vector combination for drought-tolerant index (DTI) as well as the stress-tolerant index (STI). The results of MLP, SVM, MLP-GA, and SVM-GA algorithms were compared based on statistical indices and visual interpretation that have satisfactory for prediction of the drought-tolerant index and stress-tolerant index in maize crop. It has also seemed that genetic algorithm-based hybrid models (MLP-GA and SVM-GA) were found a better prediction of the droughttolerant index and stress-tolerant index in maize crop. Similarly, the SVM-GA model has the highest potential to forecast the DTI and STI in maize crops as compared to MLP, SVM, MLP-GA models.
\end{abstract}

Keywords: Drought tolerance index; Stress tolerance index; MLP; SVM; MLP-GA; SVM-GA; Genetic Algorithm

\section{Introduction}

Agriculture is vulnerable to climate change and at the global level, climate change is a major concern and climate change has adverse impacts on food production, quality, and 
food security [1]. The importance of staple food as cereals among people around the world is widely recognized. Maize (Zea mays subsp. mays) belongs to the Poaceae family, which is an important staple cereal crop for food, livestock feed, and biofuels at a global level. After the green revolution, again there is a challenge as well as responsibility in front of plant breeders to increase the production of maize to provide sufficient food for the fastgrowing world population. As data published by USDA, the world's maize production was 1070.51 metric tonnes during 2016-17 and the total acreage of maize production was 183.76 million hectares with the productivity of 5.83 tonnes/ hectare. Maize is the third most important cereal crop in India after rice and wheat. India is one of the major maize producing countries in the world with a production of 26 million tonnes and productivity of 2.71 tonnes per hectare in the year 2016-17, from an area of about 9.6 million hectares.

The maize crop is sensitive to several biotic and abiotic stresses. One of the main deterrents for considerable yield loss in maize is its susceptibility to abiotic stresses, including drought, which leads to reduce production. Maize is growing across the globe and the most deleterious among abiotic stresses, which restrict crop production, is considered as drought stress [2] and 20-25 percent of maize cultivation area is affected by drought throughout the world [3]. To feed the empty stomach of the world's growing population, there is an urgent need to develop climate-proofing genotypes to combat these abiotic stresses. The world's agriculture is facing different abiotic problems in a different area and the large area is affected by moisture stress during the life span of crop due to the erratic behaviour of climate. The focus should be given to simplifying the concept of the genetics of complex mechanisms of drought.

Therefore, the term and mechanism of drought should be well understood. Drought in terms of agriculture may be defined as a specific condition whereby there is the unavailability of adequate moisture content in the soil at different stages of plant growth to meet their needs [4]. The meaning of drought tolerance in the case of any plant species is generally understood in terms of their survival, but when we talk about crop species, productivity should always be determinant [5]. The mechanism of drought tolerance is quite complex and complicated due to the involvements of several factors and hence, therefore, selection for drought tolerance is always a tedious job due to interactions between genotypes and environmental factors, which restricts knowledge about the mechanism, contribution of different factors and interactions among factors of tolerance [6]. Under drought stress, there is a significant change in the physiology of cells and finally, the response of crop species ultimately affects leaf water content, transpiration rate, leaf rolling, photosynthesis, and water use efficiency (WUE). Due to a lack of sufficient information about mechanisms of drought tolerance, drought tolerance can be quantified based on grain yield under dry conditions [7]. The nature of the drought is unpredictable and erratic. Now the recurrent nature becomes a permanent feature under the global climate change scenario. Therefore, it is an urgent need to predict the occurrence of drought stress. Hence, our hypothesis was to develop a novel hybrid model to predict the droughttolerant indices and stress-tolerant indices.

Artificial intelligence is widely employed in a variety of fields, including computer science, robotics, engineering, medical, translation, economics, business, and psychology. Several investigations in the literature reveal that artificial intelligence in modeling approaches produce findings that seem to be close to the actual information when solving linear, complex, as well as other systems. We review the present state-of-the-art and advancements in artificial intelligence modeling for various natural processes such as wilting point [8], soil temperature [9,10], soil moisture [11], evaporation [12-15], soil permeability [16-18] evapotranspiration [19], silt [20], solar radiation [21], water quality [22], stage-discharge [23] and runoff [24] that affect to crops at different stages. It was found that no effective model was developed in past to predict drought and stress-tolerant indices for any crops except the regression-based model. The prediction potential of the regression-based model was very low as compared to artificial intelligence (AI) $[25,26]$.

Therefore, artificial intelligence techniques are used to develop a reliable model for the prediction of drought and stress-tolerant indices in the current study. Multilayer 
perceptron (MLP) and support vector machine are the most popular and wildly used artificial intelligence techniques in the last few decades to solved various problems. Darbandi and Pourhosseini [27] used the Gamma test to determine the optimal input arrangement of the systems, and subsequently, MLP and hybrid multilayer perceptron were also used to estimate periodic stream flows for such a series of time increments employing actual data. The results suggested that the hybrid multilayer perceptron model was acceptable for periodic stream flows modeling in the research area, while the MLP model performs poorly in comparison to the hybrid multilayer perceptron model. Heddam et al. [28] studied the utility and capability of four different AI models. The results of AI models showed to be strong and useful techniques for forecasting pigment concentration concentrations using simply water quality indicators as variables. Oliveira et al. [29] studied the applicability of MLP and remote sensing for the estimation of coffee tree volume using vegetative indices from various areas of plants. The results suggested that the performance of MLP and remote sensing were satisfactory for the estimation of coffee tree volume. Mehmet et al. [30] used the SVM and MLP model for the prediction of drought and also compared the potential of empirical decomposition and the different wavelet networks. Sareh et al. [31] studied the five different AI and Hybrid AI algorithms to predict water infiltration. The results indicated that the performance of hybrid AI models, as well as AI models, were seen to be good, and also hybrid AI models perform well in comparison to conventional AI models. After review the potential application of artificial intelligence and in various fields, we decide that multilayer perceptron, support vector machine, and their hybrid with genetic algorithm models can be used to develop a novel prediction model. It is necessary to develop a novel approach for forecasting drought and stress tolerance indices for crops. Hence, our hypothesis was to develop a novel hybrid model for the prediction of the drought-tolerant indices and stress-tolerant indices based on multilayer perceptron (MLP), support vector machine (SVM), genetic algorithm-based hybrid multilayer perceptron (MLP-GA), genetic algorithm-based hybrid support vector machine (SVM-GA) models. Also, superior input-output combinations were developed via gamma test.

\section{Materials and Methods}

\subsection{Data collection}

The current investigation was performed at N. E. Borlaug Crop Research Centre, G. B. Pant University of Agriculture and Technology, Pantnagar, Uttarakhand. The planting materials were wild progenitor teosinte (Z. mays ssp. parviglumis) and a maize inbred line DI-103. Teosinte as a pollen parent and maize inbred line DI-103 were crossed in Kharif, 2015 and one backcrossed with DI-103 as a recurrent parent to develop $\mathrm{BC}_{1} \mathrm{~F}_{1}$ lines and subsequently in Kharif, 2016 selfing was done to produce $203 \mathrm{BC}_{1} \mathrm{~F}_{2}$ lines which were evaluated in the rabi, 2016-2017 for drought tolerance. The present investigation comprised evaluation of 203 lines, each progeny of a single plant. The lines were sown on $13^{\text {th }}$ February 2017 in rabi season for evaluation. These lines were grown as a single row in two environmental situations i.e., irrigated and moisture stress condition during rabi, 2016-17 for the phenotyping of morpho-physiological traits associated with drought tolerance. The moisture stress was created before flowering and after sixty-one days of plant stand in the field. The rain data revealed that on $16^{\text {th }}$ May there was a rain of $29 \mathrm{~mm}$. Each row was $2 \mathrm{~m}$ long and $75 \mathrm{~cm}$ apart. The observations were taken for different morphological traits i.e., drought-tolerant index, Day of anthesis, day of silking, day to senescense, Plant Height, Ear length, Number of Kernel, gross yield per plant, stress-tolerant index to quantify the drought tolerance. The drought tolerance index and stress tolerance index were calculated with the following formula: 
$D I=\frac{Y_{S} \times\left(\frac{Y_{S}}{Y_{P}}\right)}{\bar{Y}_{S}}$

Where, DI = Drought tolerance index, $\mathrm{Ys}=$ yield in stress for each genotype, $\mathrm{Yp}=$ yield in non-stress conditions for each genotype, and $\bar{Y}_{\mathrm{S}}=$ yield mean in stress for all genotypes, $\bar{Y}_{\mathrm{p}}=$ yield mean in non-stress conditions for all genotype [21].

$$
D I=\frac{Y_{S} \times Y_{P}}{\bar{Y}_{P}}
$$

$Y_{S}=$ stress yield of a given genotype and $Y_{P}=$ optimal (potential) yield of a given genotype, $\overline{\mathrm{Y}}_{\mathrm{S}}=$ average yield of all genotypes under stress, and $\overline{\mathrm{Y}}_{\mathrm{P}}=$ average yield of all genotypes under optimal conditions [9].

\subsection{Artificial Intelligence Techniques}

Artificial Intelligence (AI) approaches based on data are showed promise in modeling and forecasting complicated natural processes, including in handling significant volumes of dynamic nature and uncertainty hidden in datasets. AI-based models with these kinds of qualities are ideally suited to agricultural, hydrological, environmental, and various modeling challenges. Probability, classification, Logic, and statistical learning-based approaches have mostly been utilized, and also various kinds of search engine optimization and mathematical programming. In the hydro-climatologic and environmental sectors, two subsets of AI have been widely used i.e., MLP and SVM. SVM stands for support vector machine. It's a data mining technique [32]. It resolves classification issues by employing a flexible representation of class borders, implementing an automatic difficulty system to minimize overfitting, and locating a single global minimum in a distributed manner [33-35]. MLP is an information processing technique that is based on a mathematical theorem and also is inspired by the natural processes of the human brain and nervous system. In a typical MLP, there are multiple layers: input, output, and hidden. Each layer contains numerous neurons, which serve as the network's basic construction pieces. The input layer contains the variables being investigated, whereas the output layer contains the system outputs. The hidden system handles a transfer function that trains and processes the nodes of input parameters [24].

\subsection{Hybrid artificial intelligence Algorithm Based on $G A$}

The GA is a stochastic optimization method that is devoid of derivatives and is inspired by natural selection and biological evolution. It outperforms other optimization methods in many ways. It can be used to solve issues in both continuous and discrete optimization. The GA method is less prone to get stuck in local minima than the AI method. It's a population-inspired computational model. It's a population genetics-inspired learning algorithm. It has primarily been utilized as a function optimizer, and that was seen to be a useful global optimization method, particularly for multi-model and noncontinuous processes. Because a large amount of literature on MLP-GA and SVM-GA has already been published in previous research [36-38], we just cited it in this part. Figures $1(A \& B)$ show a schematic representation of the suggested hybrid algorithms. That model outlines hybrid artificial intelligence (MLP and SVM) learning technique that uses the GA to optimize the network's hyperparameters. The GA tunes every one of the network's hyperparameters by encoding them onto a lengthy chromosome. The AI technique is then utilized to train the network as a result of the GA procedure. The hybrid AI learning algorithm's process is outlined Figure 1. 


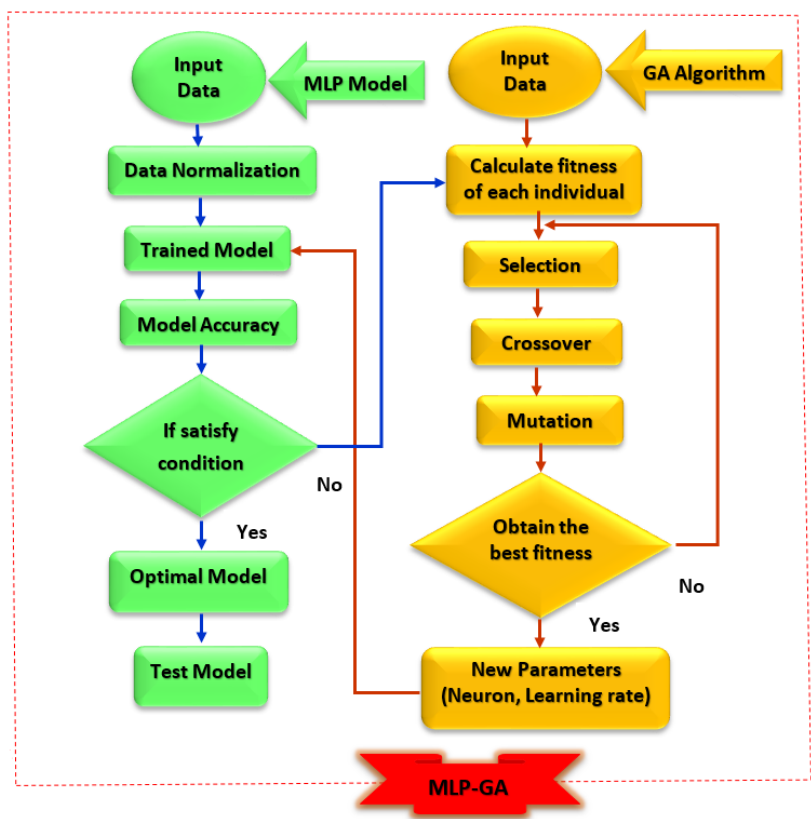

(A)

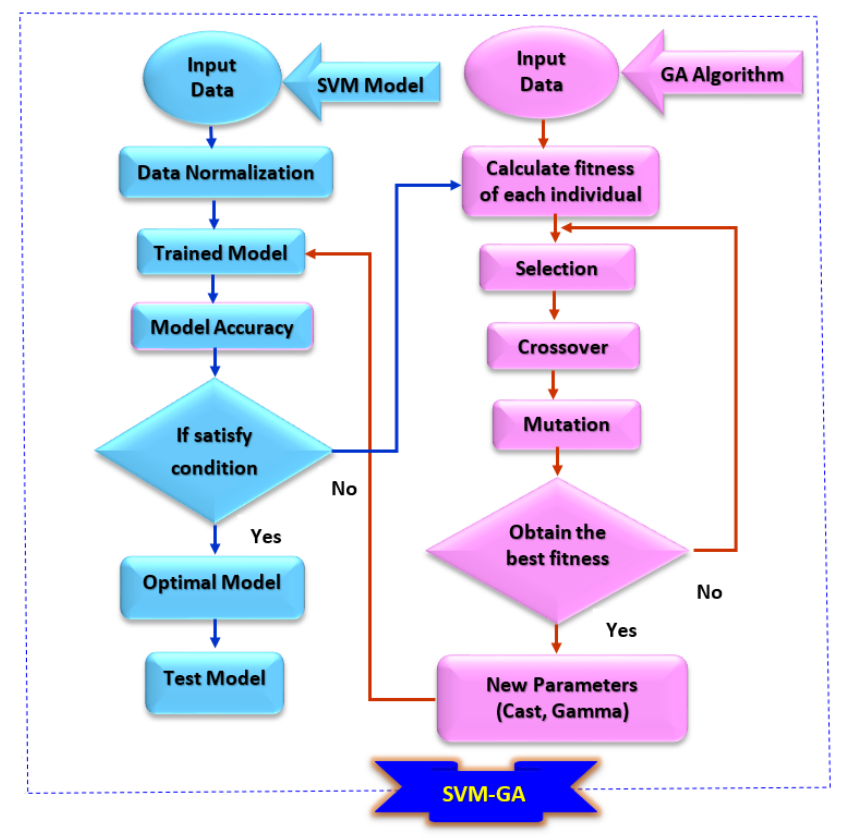

(B)

Figure 1. A \& B Flow diagram of hybrid MLP-GA and SVM-GA algorithms.

\subsection{Statistical Indices}

The performance of the developed models was evaluated based on the following indices [39].

2.4.1. Root mean square error

$$
R M S E=\sqrt{\frac{\sum_{i=1}^{n}\left(T_{t}-T_{p}\right)^{2}}{n}}
$$

Where $T_{t}$ is observed data series, $T_{p}$ is simulated data series, $n$ is the number of observations.

2.4.2. Root mean square error

$$
R^{2}=\left\lceil\frac{S S R}{S S T}\right]
$$

Where SSR is sum of squares regression, SST is sum of squares total.

2.4.3. Coefficient of efficiency

$$
C E=1-\frac{\sum_{i=1}^{n}\left(T_{t}-T_{p}\right)^{2}}{\sum_{i=1}^{n}\left(T_{p}-\bar{T}_{p}\right)^{2}}
$$
series.

Where $\bar{T}_{t}$ is average of the observed data series and $\bar{Y}_{p}$ is average of simulated data 2.4.4. Willmott's index of agreement

$$
W I=1-\frac{\sum_{i=1}^{n}\left(T_{t}-T_{p}\right)^{2}}{\sum_{i=1}^{n}\left(\left|T_{p}-\bar{T}_{t}\right|+\left|T_{t}-\bar{T}_{t}\right|\right)^{2}}
$$




\section{Results and Discussion}

\subsection{Gamma test (GT)}

The gamma test is developed a non-linear relation between information (input) and yield (output) vector based on the minimum mean squared error in data [40]. The selection of relevant information and yield vector combination is the very crucial stage in any modeling because irrelevant information vector creates a large amount of uncertainty in the model [20]. Therefore, in the present research work, we are applied GT to find an appropriate relation between yield vector i.e., drought-tolerant index (DTI) and stress-tolerant index (STI), and information vector i.e., day of anthesis, day of silking, day to scensence, plant height, ear length, number of kernel and gross yield per plant. Based on the least values of the gradient, SE, and gamma, we found an applicable relation between information and yield vector. Number of arrangements of information vector (day of anthesis, day of silking, day to scensence, plant height, ear length, number of kernel, and gross yield per plant) were examined to evaluate their impact on yield vector (drought tolerant index and stress-tolerant index) which significant amalgamations are presented in Table 1.

Table 1. Gamma test results for input variable selection.

\begin{tabular}{|c|c|c|c|c|}
\hline Model & Output/Input combination & Gamma & Gradient & SE \\
\hline D-1 & DTI=f (DOA, DOS, DTS, PHt, EL, NK, GYP) & 0.0085 & 0.0470 & 0.0029 \\
\hline D-2 & DTI=f (DOA, DOS, DTS, EL, NK, GYP) & 0.0071 & 0.0466 & 0.0020 \\
\hline D-3 & DTI=f (DOA, DOS, DTS, EL, GYP) & 0.0060 & 0.0427 & 0.0045 \\
\hline D-4 & DTI=f (DOA, DOS, DTS, EL, NK, ) & 0.0077 & 0.0538 & 0.0021 \\
\hline D-5 & DTI=f (DOA, DTS, PHt, EL, NK, GYP) & 0.0093 & 0.0468 & 0.0041 \\
\hline D-6 & DTI=f (DOA, DOS, YI, GYP) & 0.0042 & 0.0452 & 0.0016 \\
\hline D-7 & $\mathrm{STI}=\mathrm{f}(\mathrm{PHt}, \mathrm{EL}, \mathrm{NK}, \mathrm{YI}, \mathrm{GYP})$ & 0.0056 & 0.0508 & 0.0035 \\
\hline S-1 & $\mathrm{STI}=\mathrm{f}(\mathrm{DOA}, \mathrm{DOS}, \mathrm{DTS}, \mathrm{PHt}, \mathrm{EL}, \mathrm{NK}, \mathrm{GYP})$ & 0.0026 & 0.0550 & 0.0041 \\
\hline S-2 & STI =f (DOA, DOS, DTS, EL, NK, GYP) & 0.0071 & 0.0497 & 0.0037 \\
\hline S-3 & $\mathrm{STI}=\mathrm{f}(\mathrm{DOA}, \mathrm{DOS}, \mathrm{DTS}, \mathrm{EL}, \mathrm{GYP})$ & 0.0042 & 0.0689 & 0.0033 \\
\hline S-4 & $\mathrm{STI}=\mathrm{f}(\mathrm{DOA}, \mathrm{DOS}, \mathrm{DTS}, \mathrm{EL}, \mathrm{NK})$, & 0.0038 & 0.0810 & 0.0027 \\
\hline S-5 & STI =f (DOA, DTS, PHt, EL, NK, GYP) & 0.0053 & 0.0791 & 0.0035 \\
\hline S-6 & $\mathrm{STI}=\mathrm{f}(\mathrm{DOA}, \mathrm{DOS}, \mathrm{YI}, \mathrm{GYP})$ & 0.0021 & 0.0434 & 0.0026 \\
\hline S-7 & STI =f (PHt, EL, NK, YI, GYP) & 0.0062 & 0.0561 & 0.0037 \\
\hline
\end{tabular}

${ }^{*} D T I=$ drought-tolerant index, DOA=Day of anthesis, DOS= day of silking, DTS= day to scensence, PHt=Plant Height, EL = Ear length, NK= Number of kernel, GYP= gross yield per plant, YI= Yield index, STI= stress-tolerant index.

The results of the gamma test indicate that values of gamma, SE, and gradient were varied from 0.0042 to $0.0093,0.0452$ to 0.0538 , and 0.0016 to 0.0045 respectively for DTI vector; 0.0021 to $0.0062,0.0434$ to 0.0810 , and 0.0026 to 0.0037 respectively for STI vector. As a final point, the D-6 model with the arrangement of DOA, DOS, YI, and GYP information vector was elected as the final appropriate information vector amalgamation for DTI yield based on the least value of gamma indices. Similarly, the S-6 model with DOA, DOS, YI, and GYP information vector was preferred as the best information vector amalgamation for STI yield vector based on the least value of gamma indices. The gamma, SE and gradient value were originated as $0.0042,0.0452$ and 0.0016 , respectively for D-6 model; as $0.0021,0.0434$ and 0.0026 respectively for D-6 model.

\subsection{Artificial intelligence techniques}

This In this study, the two most popular artificial intelligence algorithms namely MLP and SVM, and also their hybrid with genetic algorithm were applied to predict drought-tolerant index and stress-tolerant index of maize. The parameter and algorithms which are used in the development of AI models given in Table 2. 
Table 2. Parameter of different AI models.

\begin{tabular}{|c|c|c|}
\hline Model & Parameter of the algorithms for DTI & Parameter of the algorithms for DTI \\
\hline MLP & $\begin{array}{l}\text { The transfer function is tan hyperbolic, Learning } \\
\text { rule is delta bar delta, Rate of learning is } 0.2, \text { Mo- } \\
\text { mentum values is } 0.1 \text {, Neuron in hidden layer } \\
19 \text {, Iteration is } 1000 \text {, Hidden layer in structure = } \\
1\end{array}$ & $\begin{array}{l}\text { The transfer function is tan hyperbolic, Learning } \\
\text { rule is delta bar delta, Rate of learning is } 0.2, \text { Mo- } \\
\text { mentum values is } 0.1 \text {, Neuron in hidden layer } \\
\text { 23, Iteration is } 1000 \text {, Hidden layer in structure = } \\
1\end{array}$ \\
\hline SVM & $\begin{array}{l}\text { SVM type: regression, Kernel function: Radial } \\
\text { Cast: } 11 \text {, Gamma: } 0.25\end{array}$ & $\begin{array}{l}\text { SVM type: regression, Kernel function: Radial } \\
\text { Cast: } 13 \text {, Gamma: } 0.25\end{array}$ \\
\hline MLP-GA & $\begin{array}{l}\text { GA (Population size: } 30, \text { Generation: } 100, \text { Cross- } \\
\text { over: } 0.9 \text {, Mutation: } 0.001 \text { ) }\end{array}$ & $\begin{array}{c}\text { GA (Population size: 32, Generation: 100, Cross- } \\
\text { over: } 0.9, \text { Mutation: } 0.001 \text { ) }\end{array}$ \\
\hline & $\begin{array}{c}\text { MLP (Rate of learning is } 0.2, \text { Momentum values } \\
\text { is } 0.1 \text {, Neuron in hidden layer } 32 \text {, Iteration is } \\
1000 \text {, Hidden layer in structure }=1 \text { ) }\end{array}$ & $\begin{array}{l}\text { MLP (Rate of learning is } 0.2 \text {, Momentum values } \\
\text { is } 0.1 \text {, Neuron in hidden layer is } 51 \text {, Iteration is } \\
1000 \text {, Hidden layer in structure }=1 \text { ) }\end{array}$ \\
\hline \multirow[t]{2}{*}{ SVM-GA } & $\begin{array}{l}\text { GA (Population size: 30, Generation: 100, Cross- } \\
\text { over: 0.90, Mutation: } 0.001 \text { ) }\end{array}$ & $\begin{array}{l}\text { GA (Population size: 40, Generation: 100, Cross- } \\
\text { over: 0.90, Mutation: } 0.001 \text { ) }\end{array}$ \\
\hline & $\begin{array}{l}\text { SVM (Kernel function: Radial Cast: 31, Gamma: } \\
\qquad 0.1)\end{array}$ & $\begin{array}{l}\text { SVM (Kernel function: Radial Cast: 18, Gamma: } \\
0.1)\end{array}$ \\
\hline
\end{tabular}

Based on tan hyperbolic function and delta bar delta learning rule, alone MLP model was developed, whereas, in the hybrid MLP-GA model, the hyperparameters such as learning rate, the neuron in the layer, and a hidden layer of MLP model were find based on genetic algorithm. Similarly, the alone SVM model was developed through radial function, while in the hybrid SVM-GA model, hyperparameters viz. cast and gamma were optimized using a genetic algorithm. The hybrid models were ignored to overfitting problematic of alone MLP and SVM models. It is observed that the ML model was found the best result at learning rate (0.2), momentum (0.1), neuron (19), and hidden layer (1), as a result, architecture of the best MLP model (4-19-1). Where, the first layer (4), the second layer (19), and third (1) are information vector (DOA, DOS, NK, and GYP), the neuron in the hidden layer, and yield vector (DTI) respectively. Also, the architecture of the best MLP model was 3-23-1 for the prediction of STI. The best architecture of the SVM model was 3-C11-1 and 3-C13-1 respectively, for DTI and STI prediction. The novel MLP-GA hybrid model was found the best architecture (4-32-1) at population size (30), generation (100), crossover (0.9), and mutation (0.001) for prediction of DTI in maize while the best architecture (4-51-1) at population size (32), generation (100), crossover (0.9) and mutation (0.001) for prediction of STI in maize. Correspondingly, the best architecture of SVM-GA models was 3-C31-1 and 3-C18-1 respectively, to simulate DTI and STI of maize.

The performance of developed MLP, SVM, MLP-GA, and SVM-GA models were examined based on least values of error i.e., RMSE ( 0 values show perfect prediction and $+\infty$ shows poor prediction) and largest values of NSE (values close to 1 point out good performance and 0 for poor performance), $\mathrm{R}^{2}$ ( 1 for perfect correlation and 0 for no correlation) and WI (1 for perfect agreement and 0 to no agreement). The models were also assessed based on optical observation based on line diagram, scatter plot, Taylor diagram, and discrepancy ratio scatter plot. The Taylor diagram is provided by three different indices i.e., RMSE, correlation of coefficient and standard deviation on the single visual platform for companion of the various model. The whole information and yield data were fragmented into two groups. The first group was applied for training purposes (to calibrate the model and also to find model parameters) and the second group for testing purposes (to validate the developed model).

The results of the MLP model which is obtainable in Table 3, the values of RMSE, $\mathrm{R}^{2}$, NSE, and WI during the training period are $0.041,0.839,0.836$, and 0.946 respectively and during the testing, the period is $0.025,0.839,0.799$ and 0.932 respectively for prediction DTI. Also, the SVM model has values of RMSE (0.038), R²(0.855), NSE (0.855), and WI 
(0.957) during the training period and RMSE, R², NSE, and WI were 0.023, 0.886, 0.830, and 0.936 respectively during the testing period for DTI.

Table 3. Results of different AI models for drought-tolerant index.

\begin{tabular}{ccccccccc}
\hline \multirow{2}{*}{ Model } & \multicolumn{4}{c}{ Training } & \multicolumn{3}{c}{ Testing } \\
\cline { 2 - 9 } & RMSE & R2 & NSE & WI & RMSE & R2 & NSE & WI \\
\hline MLP & 0.041 & 0.839 & 0.836 & 0.946 & 0.025 & 0.839 & 0.799 & 0.932 \\
SVM & 0.038 & 0.855 & 0.855 & 0.957 & 0.023 & 0.886 & 0.830 & 0.936 \\
MLP-GA & 0.028 & 0.921 & 0.921 & 0.978 & 0.020 & 0.910 & 0.890 & 0.964 \\
SVM-GA & 0.013 & 0.984 & 0.984 & 0.996 & 0.018 & 0.916 & 0.892 & 0.966 \\
\hline
\end{tabular}

In this study, we have also used the hybrid of MLP with a genetic algorithm (GA) and check the hybrid efficiency. In the MLP-GA model has the best values of RMSE, $\mathrm{R}^{2}$, NSE and WI were RMSE (0.013), R² (0.921), NSE (0.921), and WI (0.978) for the period of training, and for the testing period, these values were $0.020,0.910,0.890$ and 0.964 respectively. Using another hybrid of support vector machines with a genetic algorithm (SVMGA) was used to predict the DTI of maize crops. In the SVM-GA model, the best values of RMSE, R², NSE, and WI were 0.018, 0.984, 0.984, and 0.996 respectively for the training period and RMSE (0.018), R² (0.916), NSE (0.992), and WI (0.966). After comparing the results of MLP, SVM, and their hybrid models based on algebraic indices, it can say that the overall performance of artificial intelligence techniques very good for DTI prediction of maize. Also, the MLP model has poor performance as compared to the SVM model for the prediction of DTI. It also seemed that genetic-based hybrid models i.e., MLP-GA and SVM-GA models have better performance with the comparison of alone MLP and SVM models during training and testing periods for DTI prediction of maize.

In this study, stress tolerance index (STI) was predicted based on MLP, SVM, and their hybrid with genetic algorithm. In MLP and SVM models, we were used a trial-anderror approach to find the hyperparameters of MLP and SVM models while MLP-GA and SVM-GA models were applied genetic algorithms to optimize hyperparameters of MLP and SVM models. The quantitative results of MLP, SVM, MLP-GA, and SVM-GA models which are presented in Table 4, the best RMSE values were found 0.044, 0.044, 0.037, and 0.018 respectively, for MLP, SVM, MLP-GA, and SVM-GA models during training time and 0.023, 0.017, 0.015 and 0.009 respectively, for MLP, SVM, MLP-GA, and SVM-GA models during the testing time; $\mathrm{R}^{2}$ values were found $0.824,0.826,0.885$ and 0.972 during the training phase and $0.884,0.919,0.944$ and 0.978 during a testing time for MLP, SVM, MLP-GA, and SVM-GA models respectively; the maximum NSE values were 0.824, 0.826, 0.878 and 0.970 during the training period and $0.815,0.898,0.928$ and 0.973 during the testing period for MLP, SVM, MLP-GA, and SVM-GA models respectively; the best WI values were found $0.946,0.946,0.959$ and 0.991 respectively, for MLP, SVM, MLP-GA, and SVM-GA models during training time and 0.933, 0.976, 0.982 and 0.992 respectively, for MLP, SVM, MLP-GA, and SVM-GA models during testing time.

Table 4. Results of MLP and different AI models for stress-tolerant index.

\begin{tabular}{ccccccccc}
\hline \multirow{2}{*}{ Model } & \multicolumn{4}{c}{ Training } & \multicolumn{3}{c}{ Testing } \\
\cline { 2 - 9 } & RMSE & R2 & NSE & WI & RMSE & R2 & NSE & WI \\
\hline MLP & 0.044 & 0.824 & 0.824 & 0.946 & 0.023 & 0.884 & 0.815 & 0.933 \\
SVM & 0.044 & 0.826 & 0.826 & 0.946 & 0.017 & 0.919 & 0.898 & 0.976 \\
MLP-GA & 0.037 & 0.885 & 0.878 & 0.959 & 0.015 & 0.944 & 0.928 & 0.982 \\
SVM-GA & 0.018 & 0.972 & 0.970 & 0.991 & 0.009 & 0.978 & 0.973 & 0.992 \\
\hline
\end{tabular}

After comparing performance MLP, SVM, MLP-GA, and SVM-GA models, it can be concluded that the performance of all developed models was very good based on statistical indices [41]. The MLP model has poor performance as compared to the SVM model for the prediction of stress tolerance index (STI) in maize plants. Also, novel hybrid models 
based on genetic algorithms have better performance than alone MLP and SVM models. The MLP-GA model has low performance as compared to the SVM-GA model whereas better performance than MLP and SVM models. The SVM-GA model has the best performance to all applied models for the prediction of stress tolerance index (STI) in maize plants. Therefore, the SVM-GA model (4-C18-1) can be used in the future for the prediction of stress tolerance index (STI). Similar results of MLP and SVM models, as well as genetic algorithm-based MLP and SVM models, were found by many researchers. Akram and Fatemeh [36] assessed the capability of different optimization algorithms for the simulation of daily evaporation. The results showed that the performance of hybrid models superior to other models. Stamenković [42] used the MLP and SVM model for the simulation of phosphate and nitrate in surface water. The performance of both models was good to predict the water quality of surface water. Rahgoshay et al. [43] studied suspended sediment concentration using SVM and SVM-GA models. It was suggested that the performance of SVM was improved after applying a genetic algorithm for the prediction of suspended sediment concentration. Massah et al. [44] used SVM and hybrid SVM models to predict the yield of kiwifruit. The results indicated that the potential of the SVM improved with a hybrid algorithm for the prediction of the yield of kiwifruit.

The performance of developed MLP, SVM, MLP-GA, and SVM-GA models was also evaluated based on qualitative assessment. The qualitative assessment was done through visual observation of line diagram, scatter plot, Taylor diagram, and discrepancy ratio scatter plot. The line diagram indicates from Figure 2 and 3 that the predicted drought tolerance index (DTI) by MLP and SVM models slightly deviates from observed drought tolerance index whereas predicted drought tolerance index through MLP-GA and SVMGA models similar to observed predicted drought tolerance index. Similarly, scatter plots shows that the predicted values of drought tolerance index through MLP and SVM models were deviated from the 1:1 $(X=Y)$ line but predicted values of drought tolerance index through MLP-GA and SVM-GA models were less deviation. It was also depicted from Figure 4 and 5 (Taylor diagram during training and testing periods), MLP and SVM models have high RMSE and standard deviation form observed and low correlation coefficient than novel hybrid models. The discrepancy ratio value ranges from -1 to 1 , minus value indicates under prediction, plus value shows over prediction and zero discrepancy ration indicates perfect prediction by models to observe $[10,20]$. In the same way, it was observed from Figure 6 and 7, MLP and SVM models have a high deviation of discrepancy ration value from zero in comparison to hybrid MLP-GA and SVM-GA models.
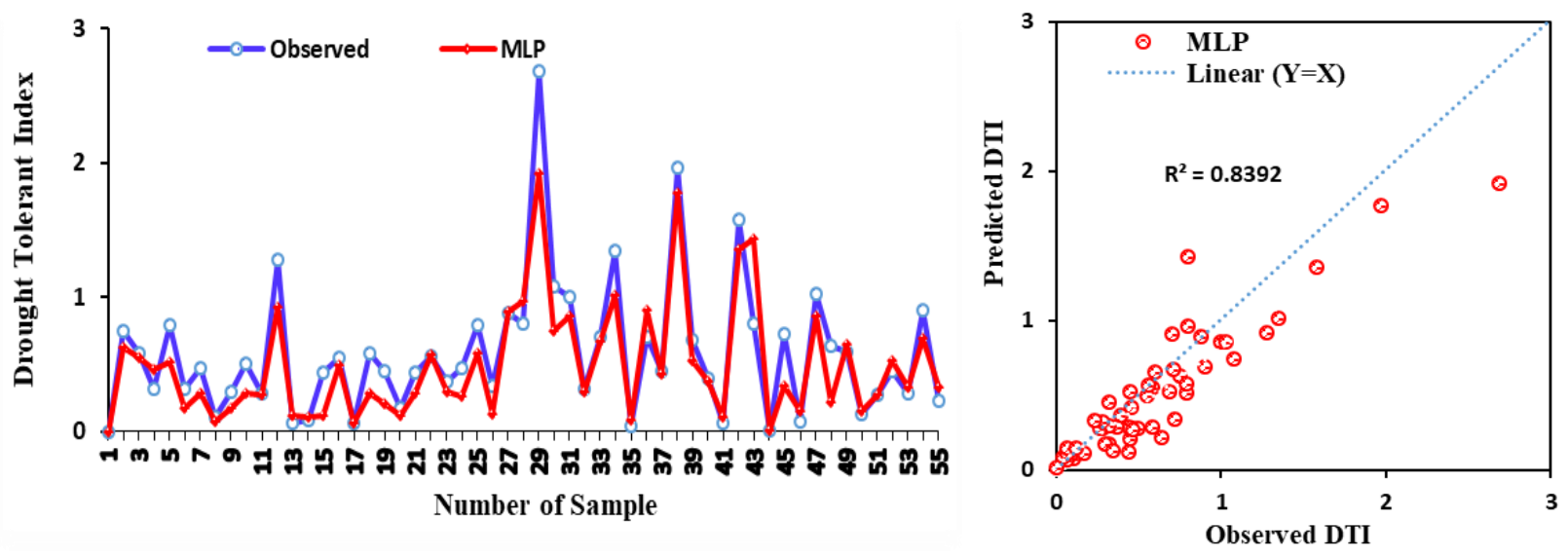

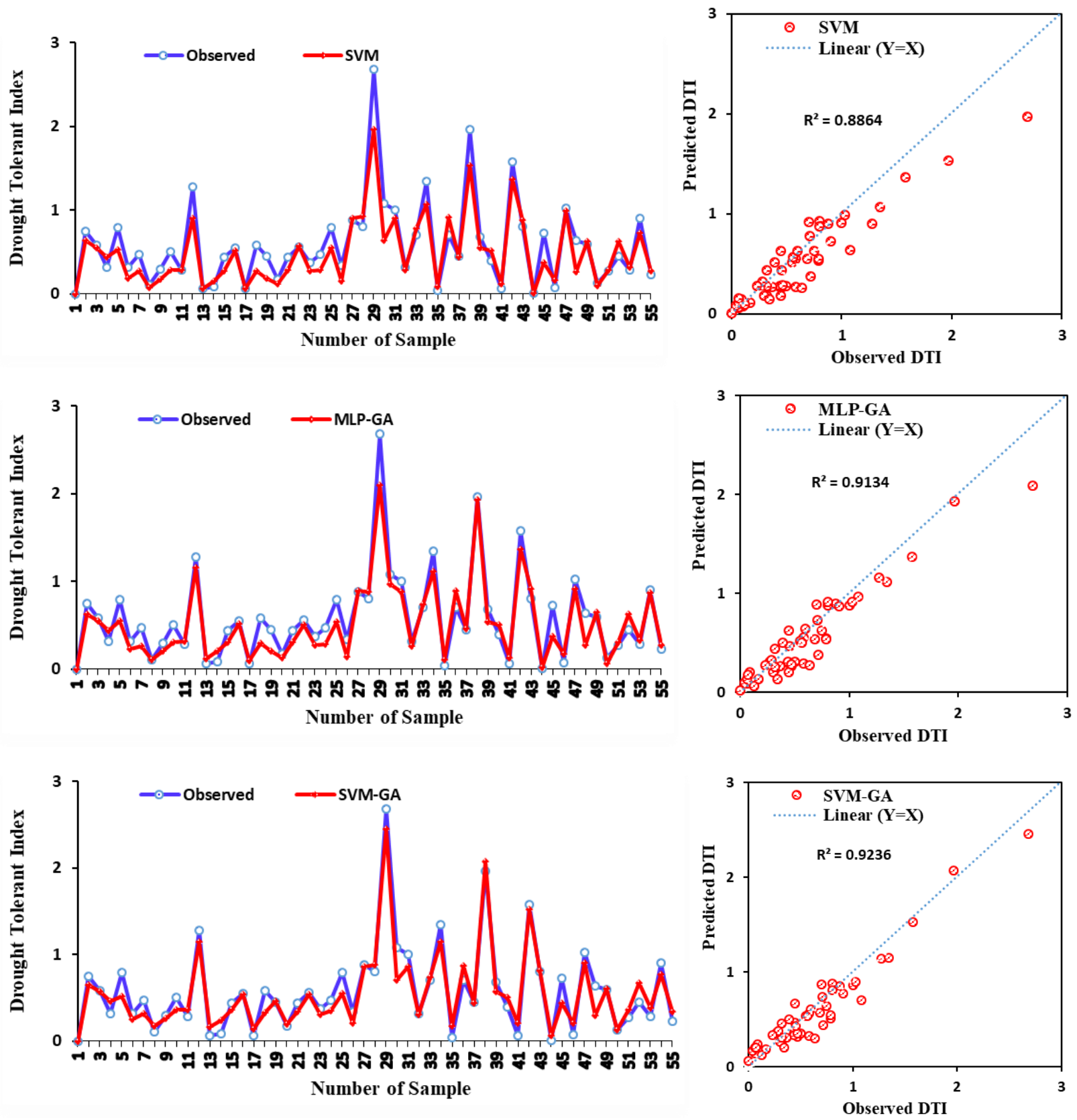

Figure 3. Line and scatter diagram of different artificial intelligence techniques for drought tolerant index.

Overall visual interpretation indicates that the SVM-GA model was accurately predicted to stress tolerance index and stress tolerance index than other models. From Fig. 8, the surface 3D diagram plots of stress tolerance index and stress tolerance index with yield index and gross yield production indicate that stress tolerance index and stress tolerance index surface 3D plots of observed and predicted were similar with each other. 

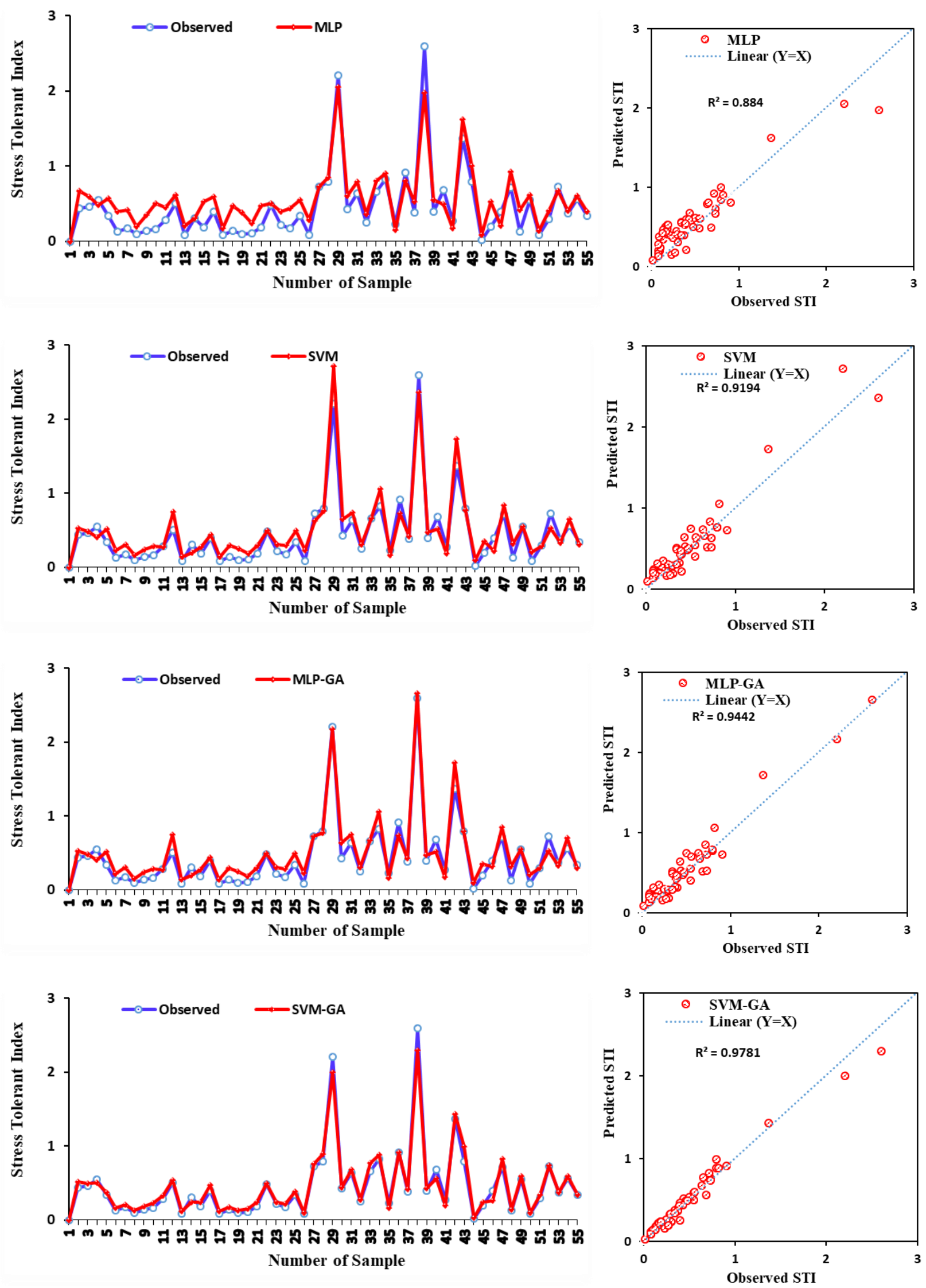

Figure. 3. Line and scatter diagram of different artificial intelligence techniques for stress tolerant index. 

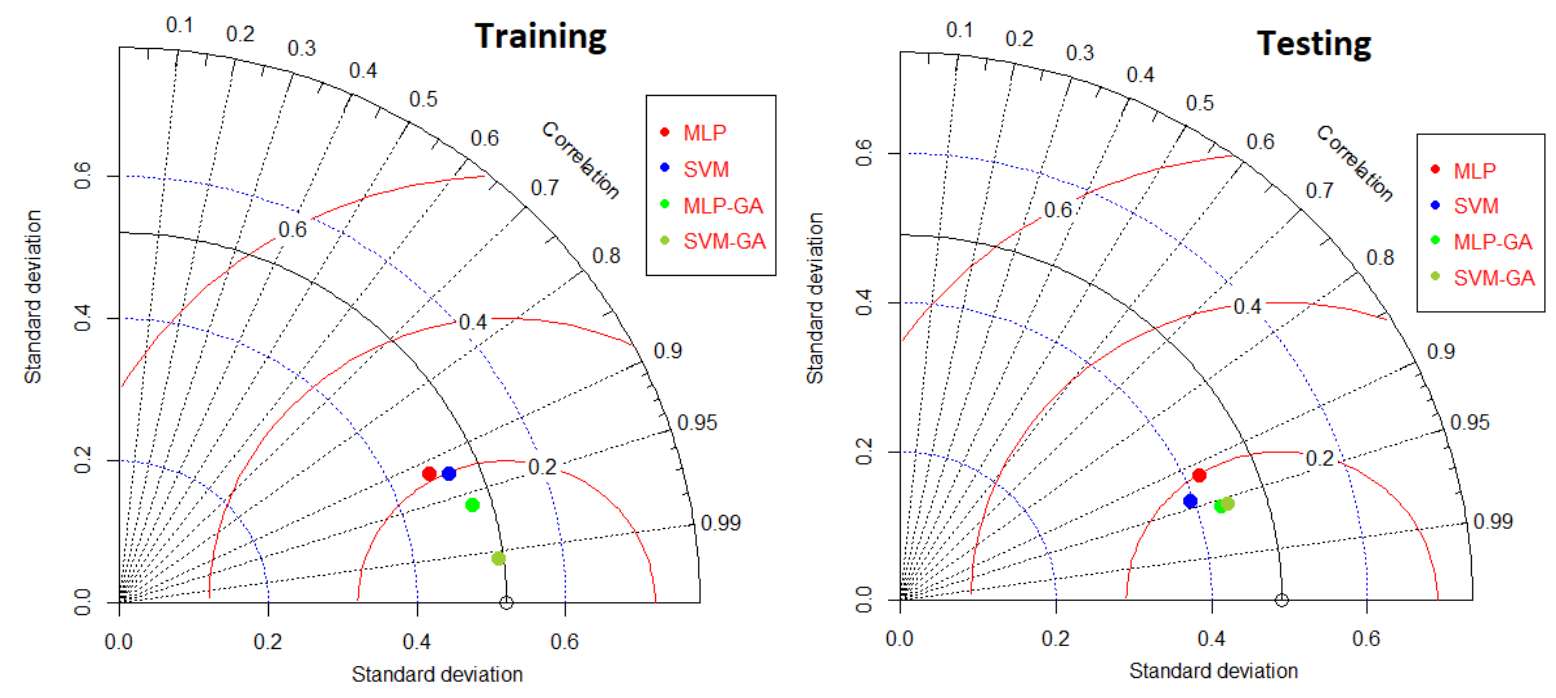

Figure 4. Taylor diagram of different artificial intelligence techniques for drought tolerant index.
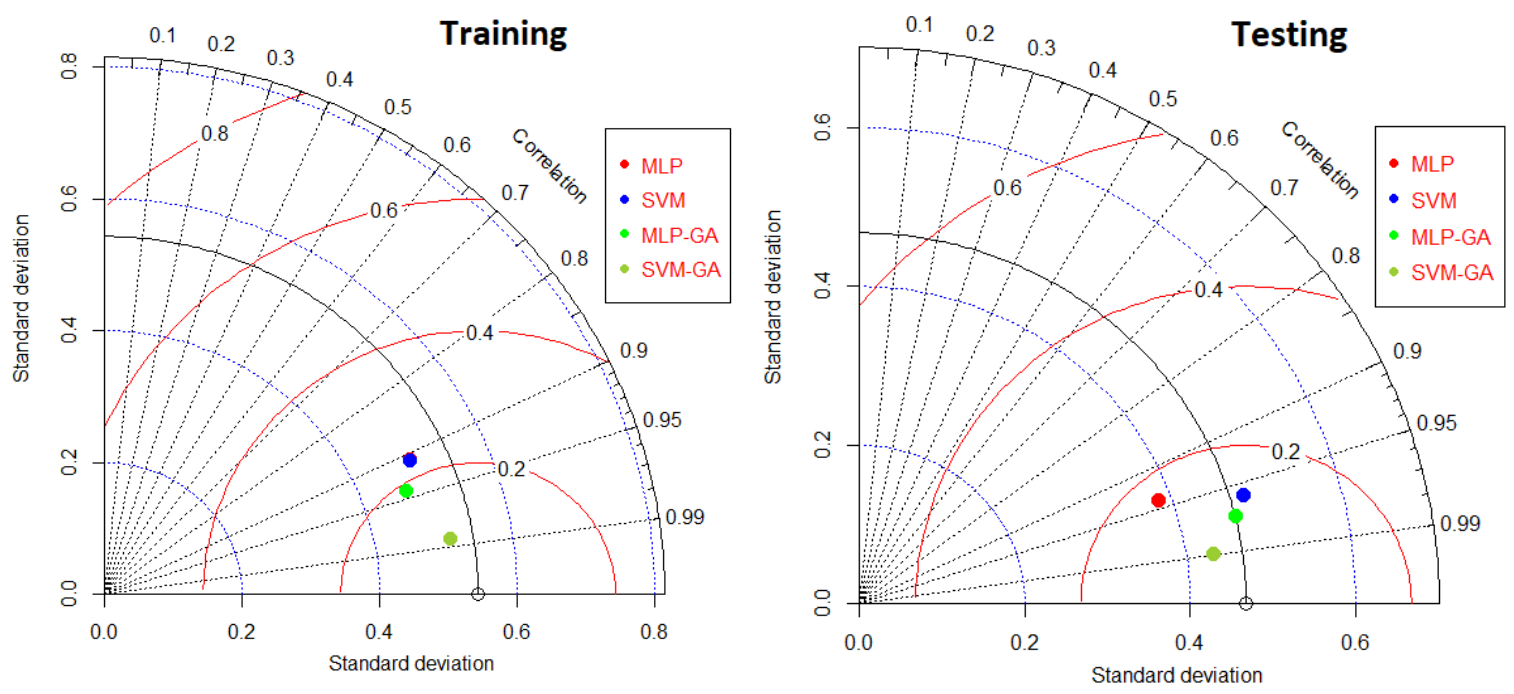

Figure 5. Taylor diagram of different artificial intelligence techniques for stress tolerant index stress.
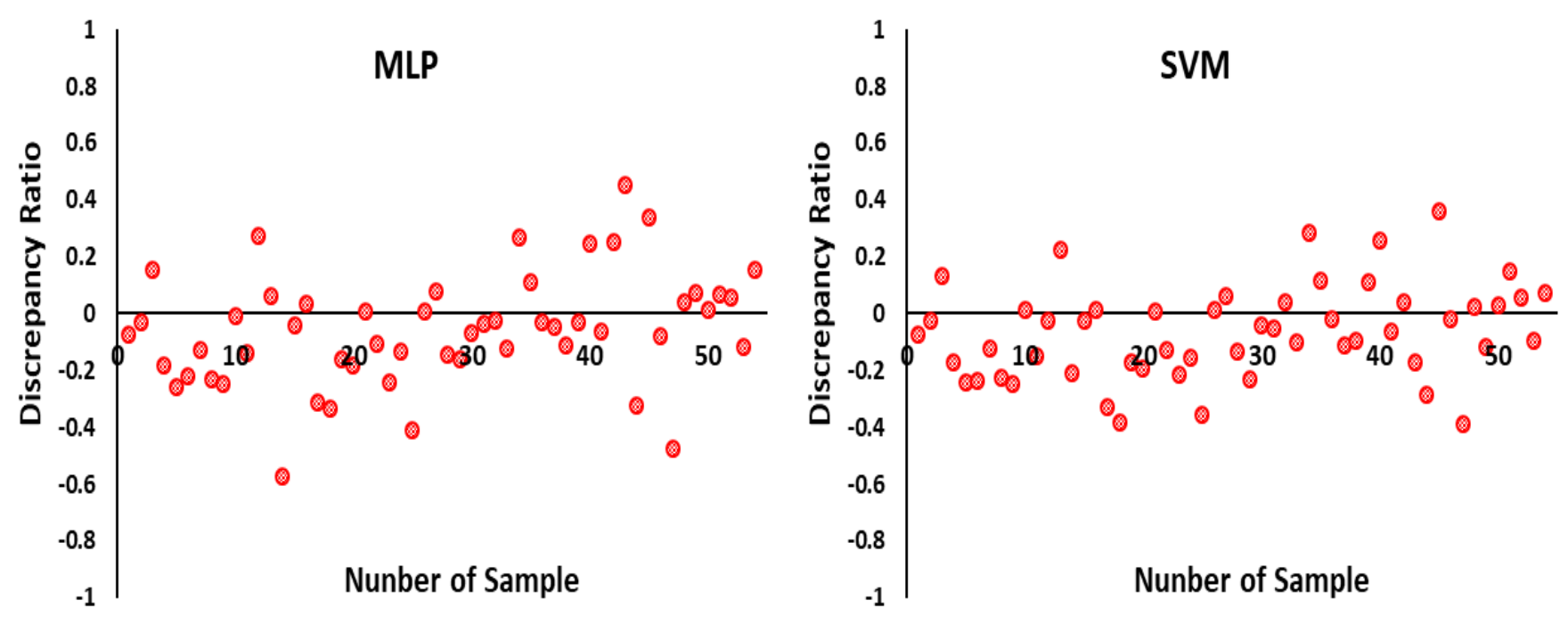

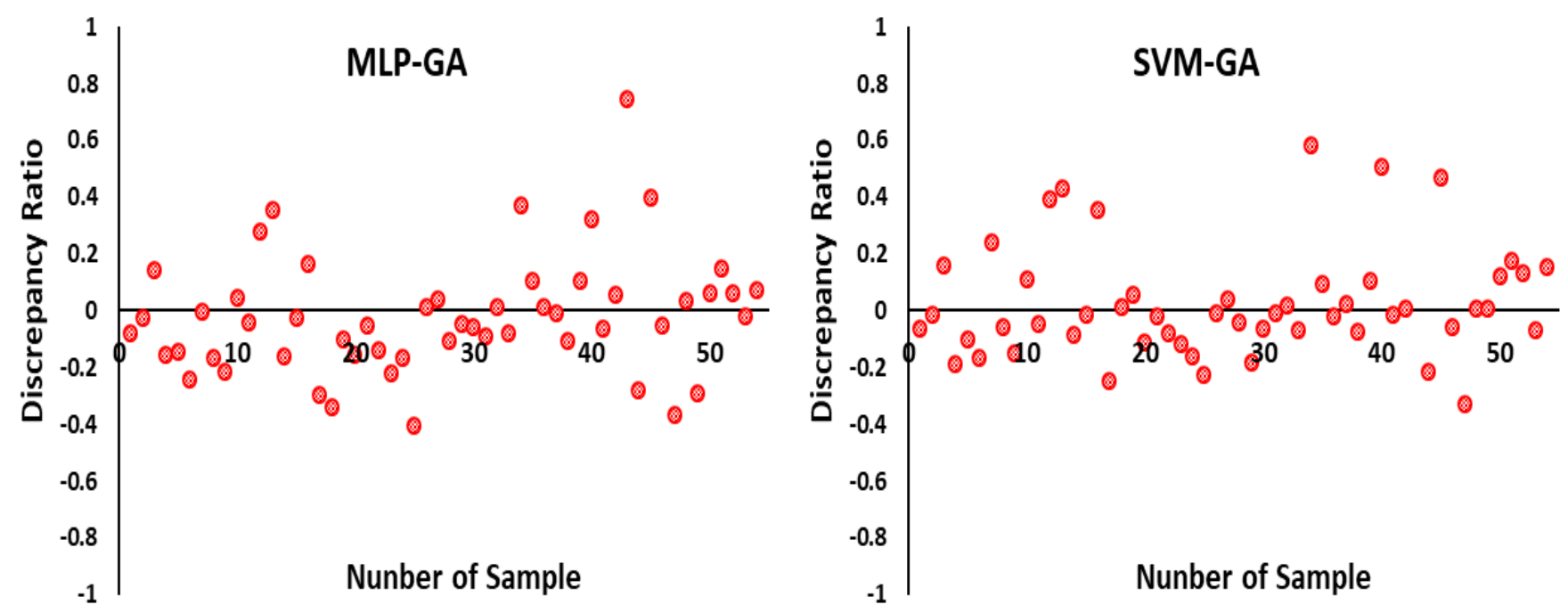

Figure 6. Discrepancy ratio scatter plot of different artificial intelligence techniques for drought tolerant index.
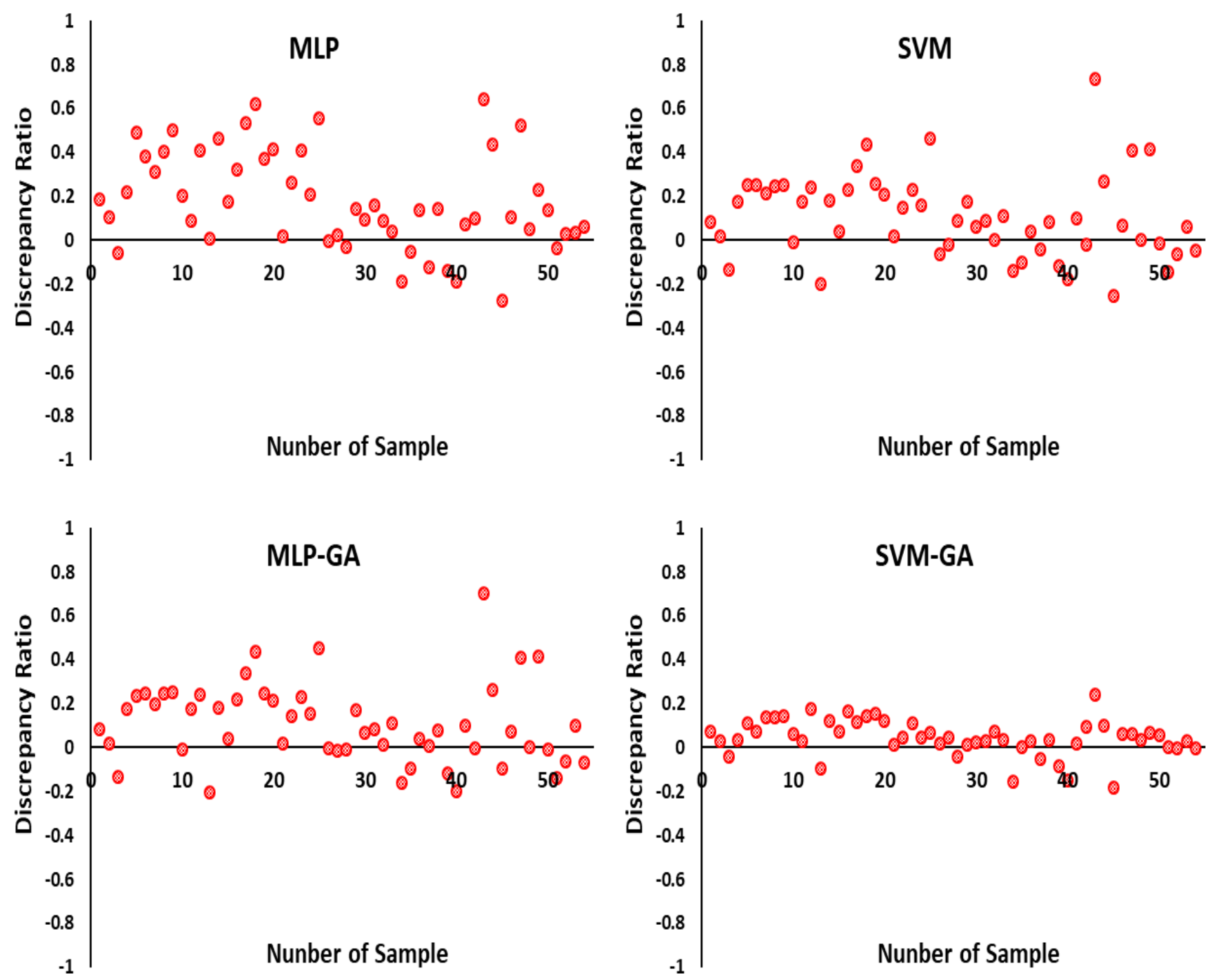

Figure 7. Discrepancy ratio scatter plot of different artificial intelligence techniques for stress tolerant index. 

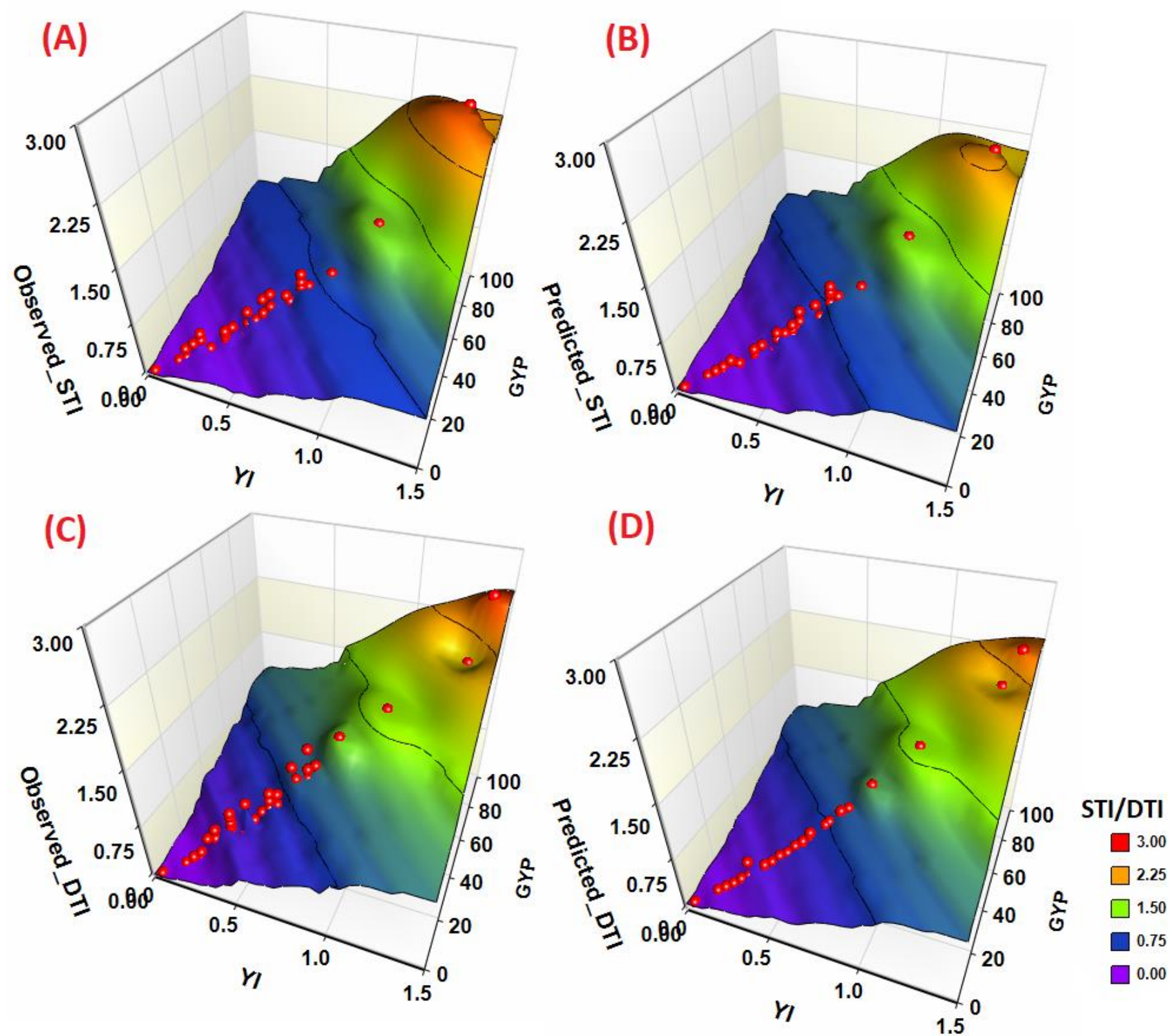

Figure 8. Surface 3D plots of stress tolerance index and drought tolerance index with yield index and gross yield production for observed STI (A), predicted STI (B), observed DTI (C) and predicted DTI (D) respectively.

Also, concluded that stress tolerance index and stress tolerance index were increased with increasing value of yield index and gross yield production. The results of this research reflected that this can be considered as a solution to predict agricultural drought concerning maize crops. To decide strategies regarding drought, monitoring of drought is an essential element that will provide us early warnings of drought. National food security is the priority of any nation and for that prediction of drought will help the agriculture sector for better management of drought. The loss in the production of crops like maize due to drought can depend on the intensity of drought, their duration, and the most important the growth stages of crop plants. This novel hybrid model will help to predict drought in maize crop and give information which might be helpful for farmers to avoid or minimize the production loss. The novel hybrid model is prepared based on data input of teosinte introgressed maize lines.

The novel hybrid model will help in the assessment and development of drought stress tolerant varieties by predicting the drought and stress tolerance indices. Therefore, plant breeders will able to evaluate the genetic worth of the genotypes. This will fulfil the prime goal of a farmer i.e., development of such varieties which will grow in the wide 
range of climatic conditions. This drought and stress tolerance indices predicting model will provide the assistance in the identification along with selection of highly stable genotypes and high-yielding under the drought condition. The combination of drought and stress tolerance indices may be more valuable selection criteria for improving drought tolerance.

\section{Conclusions}

The important tools to monitor and measure drought events are the drought-tolerant index and stress-tolerant index. In this study, four conventional and hybrid artificial intelligence algorithms were applied to predict drought tolerance and stress tolerance indices for maize crops. Also, gamma test-based input and output vectors were selected. It was indicated from gamma test results that the arrangement of DOA, DOS, YI, and GYP information vector was elected as the final appropriate information vector amalgamation for DTI yield based on the least value of gamma indices. Similarly, DOA, DOS, YI, and GYP information vectors were preferred as the best information vector amalgamation for STI yield vector based on the least value of gamma indices. It was concluded based on statistical indices and visual interpretation that results of MLP, SVM, MLP-GA, and SVMGA algorithms have satisfactory for prediction of the drought-tolerant index and stresstolerant index in maize crop. It has also appeared that genetic algorithm-based hybrid models (MLP-GA and SVM-GA) were found to better prediction of the drought-tolerant index and stress-tolerant index in maize crops. Similarly, the SVM-GA model has the highest potential to forecast the DTI and STI in maize crops as compared to MLP, SVM, MLP-GA models. After analysing the results of MLP, SVM, MLP-GA, and SVM-GA algorithms, it can say that artificial intelligence-based algorithms can be used for the prediction of drought-tolerant and stress-tolerant indices in maize crop. It is also suggested that artificial intelligence-based algorithms can be used in the future for forecasting droughttolerant and stress-tolerant indices in different crops. The effect of drought on crop production can be evaluated through crop models. These models are nothing but mathematical equation give information about the relationships between crop growth, production, management technology, and climatic condition. The present research represents the use of a novel hybrid model for predicting drought-tolerant index and stress-tolerant index to assess the drought on maize yield loss and this model will be very helpful for researchers and policymakers.

Author Contributions: Conceptualization, V.K.S., D.K.V. and B.S.; methodology, V.K.S.; software, V.K.S. and D.K.V; validation, A.K.; formal analysis, A.K., V.P.S. and B.S.; investigation, N.K.S.; resources, N.K.S.; data curation, V.P.S.; writing-original draft preparation, V.K.S., S.A., A.J. and A.K.; writing - review and editing, V.P.S., N.K.S. and N.A.-A.; visualization, V.K.S. and D.K.V.; supervision, V.P.S. and N.K.S.; project administration, V.K.S. and N.K.S.; funding acquisition, N.A.-A. All authors have read and agreed to the published version of the manuscript.

Funding: This research received no external funding.

Data Availability Statement: Not applicable

Acknowledgments: We acknowledge the Director Experiment Station and Head, Department of Genetics and Plant Breeding, Govind Ballabh Pant University of Agriculture \& Technology, Pantnagar for proving experimental facilities.

Conflicts of Interest: The authors declare no conflict of interest.

\section{References}

1. Kumar, A.; Singh, N.K.; Adhikari, S.; Joshi, A. Morphological and molecular characterization of teosinte derived maize population. Indian J. Genet. Plant Breed. 2019, 79, 670-677, doi:10.31742/IJGPB.79.4.4.

2. Alahdadi, I.; Oraki, H.; Khajani, F.P. Effect of water stress on yield and yield components of sunflower hybrids. African J. Biotechnol. 2011, 10, 6504-6509, doi:10.4314/ajb.v10i34. 
3. Golbashy, M.; Ebrahimi, M.; Khorasani, S.K.; Choukan, R. Evaluation of drought tolerance of some corn (Zea mays L.) hybrids in Iran. African J. Agric. Res. 2010, 5, 2714-2719, doi:https://doi.org/10.5897/AJAR.9000310.

4. FAO Crop water information: Maize Available online: http://www.fao.org/nr/water/cropinfo-maize.html.

5. Passioura, J.B. Roots and drought resistance. In Developments in Agricultural and Managed Forest Ecology; Elsevier, 1983; Vol. 12, pp. 265-280 ISBN 0166-2287.

6. Messmer, R.E. The genetic dissection of key factors involved in the drought tolerance of tropical maize (Zea mays L.), Doctoral dissertation, ETH Zurich, 2006.

7. Fischer, R.A.; Maurer, R. Drought resistance in spring wheat cultivars. I. Grain yield responses. Aust. J. Agric. Res. 1978, 29, 897-912.

8. Ghorbani, M.A.; Shamshirband, S.; Haghi, D.Z.; Azani, A.; Bonakdari, H.; Ebtehaj, I. Application of firefly algorithm-based support vector machines for prediction of field capacity and permanent wilting point. Soil Tillage Res. 2017, 172, 32-38, doi:https://doi.org/10.1016/j.still.2017.04.009.

9. Kim, S.; Singh, V.P. Modeling daily soil temperature using data-driven models and spatial distribution. Theor. Appl. Climatol. 2014, 118, 465-479, doi:10.1007/s00704-013-1065-z.

10. Singh, V.K.; Singh, B.P.; Kisi, O.; Kushwaha, D.P. Spatial and multi-depth temporal soil temperature assessment by assimilating satellite imagery, artificial intelligence and regression based models in arid area. Comput. Electron. Agric. 2018, 150, 205-219, doi:https://doi.org/10.1016/j.compag.2018.04.019.

11. Gu, Z.; Zhu, T.; Jiao, X.; Xu, J.; Qi, Z. Neural network soil moisture model for irrigation scheduling. Comput. Electron. Agric. 2021, 180, 105801, doi:https://doi.org/10.1016/j.compag.2020.105801.

12. Bhagwat, S.; Kashyap, P.S.; Singh, B.P.; Singh, V.K. Daily pan evaporation modeling in hilly region of Uttarakhand using artificial neural network. Indian J. Ecol. 2017, 44, 467-473.

13. Keshtegar, B.; Piri, J.; Kisi, O. A nonlinear mathematical modeling of daily pan evaporation based on conjugate gradient method. Comput. Electron. Agric. 2016, 127, 120-130, doi:https://doi.org/10.1016/j.compag.2016.05.018.

14. Khosravi, K.; Daggupati, P.; Alami, M.T.; Awadh, S.M.; Ghareb, M.I.; Panahi, M.; Pham, B.T.; Rezaie, F.; Qi, C.; Yaseen, Z.M. Meteorological data mining and hybrid data-intelligence models for reference evaporation simulation: A case study in Iraq. Comput. Electron. Agric. 2019, 167, 105041, doi:https://doi.org/10.1016/j.compag.2019.105041.

15. Kushwaha, N.L.; Rajput, J.; Elbeltagi, A.; Elnaggar, A.Y.; Sena, D.R.; Vishwakarma, D.K.; Mani, I.; Hussein, E.E. Data Intelligence Model and Meta-Heuristic Algorithms-Based Pan Evaporation Modelling in Two Different Agro-Climatic Zones: A Case Study from Northern India. Atmosphere (Basel). 2021, 12, 1654.

16. Ramdas, S.; Singh, R.; Sharma, I. Exploring the performance of wheat production in India. J. Wheat Res. 2020, 4, 37-44.

17. Sihag, P.; Tiwari, N.K.; Ranjan, S. Prediction of unsaturated hydraulic conductivity using adaptive neuro-fuzzy inference system (ANFIS). ISH J. Hydraul. Eng. 2019, 25, 132-142.

18. Sihag, P.; Tiwari, N.K.; Ranjan, S. Prediction of unsaturated hydraulic conductivity using adaptive neuro- fuzzy inference system (ANFIS). ISH J. Hydraul. Eng. 2019, 25, 132-142, doi:10.1080/09715010.2017.1381861.

19. Tang, D.; Feng, Y.; Gong, D.; Hao, W.; Cui, N. Evaluation of artificial intelligence models for actual crop evapotranspiration modeling in mulched and non-mulched maize croplands. Comput. Electron. Agric. 2018, 152, 375-384, doi:https://doi.org/10.1016/j.compag.2018.07.029.

20. Singh, V.K.; Kumar, D.; Kashyap, P.S.; Kisi, O. Simulation of suspended sediment based on gamma test, heuristic, and regression-based techniques. Environ. Earth Sci. 2018, 77, 708, doi:10.1007/s12665-018-7892-6.

21. Citakoglu, H. Comparison of artificial intelligence techniques via empirical equations for prediction of solar radiation. Comput. Electron. Agric. 2015, 118, 28-37, doi:https://doi.org/10.1016/j.compag.2015.08.020. techniques for spatial evaluation of groundwater quality variables. J. Clean. Prod. 2020, 276, 124206, 
doi:https://doi.org/10.1016/j.jclepro.2020.124206.

23. Shukla, R.; Kumar, P.; Vishwakarma, D.K.; Ali, R.; Kumar, R.; Kuriqi, A. Modeling of stage-discharge using back propagation ANN-, ANFIS-, and WANN-based computing techniques. Theor. Appl. Climatol. 2021, doi:10.1007/s00704-021-03863-y.

24. Singh, V.K.; Singh, B.P.; Kumar, A.; Vivekanand A Comparative Study of Artificial Intelligence and Conventional Techniques for Rainfall-Runoff Modeling. Int. J. Agric. Eng. Vol 10, No 2 2017, 10, 441-449, doi:DOI: 10.15740/HAS/IJAE/10.2/441-449.

25. Singh, V.K.; Kumar, P.; Singh, B.P.; Malik, A. A comparative study of adaptive neuro fuzzy inference system (ANFIS) and multiple linear regression (MLR) for rainfall-runoff modelling. Int. J. Nat. Sci. 2016, 7, 714-723.

26. Singh, V.K.; Kumar, P.; Singh, B.P. Rainfall-runoff modeling using artificial neural networks (ANNs) and multiple linear regression (MLR) techniques. Indian J. Ecol. 2016, 43, 436-442.

27. Darbandi, S.; Pourhosseini, F.A. River flow simulation using a multilayer perceptron-firefly algorithm model. Appl. Water Sci. 2018, 8, 85, doi:10.1007/s13201-018-0713-y.

28. Heddam, S.; Sanikhani, H.; Kisi, O. Application of artificial intelligence to estimate phycocyanin pigment concentration using water quality data: a comparative study. Appl. Water Sci. 2019, 9, 164, doi:10.1007/s13201-019-1044-3.

29. de Oliveira, M.F.; dos Santos, A.F.; Kazama, E.H.; de Souza Rolim, G.; da Silva, R.P. Determination of application volume for coffee plantations using artificial neural networks and remote sensing. Comput. Electron. Agric. 2021, $184,106096$.

30. Özger, M.; Başakın, E.E.; Ekmekcioğlu, Ö.; Hacısüleyman, V. Comparison of wavelet and empirical mode decomposition hybrid models in drought prediction. Comput. Electron. Agric. 2020, 179, 105851, doi:https://doi.org/10.1016/j.compag.2020.105851.

31. Sayari, S.; Mahdavi-Meymand, A.; Zounemat-Kermani, M. Irrigation water infiltration modeling using machine learning. Comput. Electron. Agric. 2021, 180, 105921, doi:https://doi.org/10.1016/j.compag.2020.105921.

32. Tabari, H.; Kisi, O.; Ezani, A.; Talaee, P.H. SVM, ANFIS, regression and climate based models for reference evapotranspiration modeling using limited climatic data in a semi-arid highland environment. J. Hydrol. 2012, 444, 78-89, doi:https://doi.org/10.1016/j.jhydrol.2012.04.007.

33. Tabari, H.; Martinez, C.; Ezani, A.; Hosseinzadeh Talaee, P. Applicability of support vector machines and adaptive neurofuzzy inference system for modeling potato crop evapotranspiration. Irrig. Sci. 2013, 31, 575-588, doi:10.1007/s00271012-0332-6.

34. Wen, X.; Si, J.; He, Z.; Wu, J.; Shao, H.; Yu, H. Support-Vector-Machine-Based Models for Modeling Daily Reference Evapotranspiration With Limited Climatic Data in Extreme Arid Regions. Water Resour. Manag. 2015, 29, 3195-3209, doi:10.1007/s11269-015-0990-2.

35. Shiri, J.; Nazemi, A.H.; Sadraddini, A.A.; Landeras, G.; Kisi, O.; Fakheri Fard, A.; Marti, P. Comparison of heuristic and empirical approaches for estimating reference evapotranspiration from limited inputs in Iran. Comput. Electron. Agric. 2014, 108, 230-241, doi:https://doi.org/10.1016/j.compag.2014.08.007.

36. Seifi, A.; Soroush, F. Pan evaporation estimation and derivation of explicit optimized equations by novel hybrid metaheuristic ANN based methods in different climates of Iran. Comput. Electron. Agric. 2020, 173, 105418, doi:https://doi.org/10.1016/j.compag.2020.105418.

37. Oh, M.S.; Chen, Z.; Jahanshiri, E.; Isa, D.; Wong, Y.W. An economic feasibility assessment framework for underutilised crops using Support Vector Machine. Comput. Electron. Agric. 2020, 168, 105116, doi:https://doi.org/10.1016/j.compag.2019.105116.

38. Pourmohammadali, B.; Salehi, M.H.; Hosseinifard, S.J.; Boroujeni, I.E.; Shirani, H. Studying the relationships between nutrients in pistachio leaves and its yield using hybrid GA-ANN model-based feature selection. Comput. Electron. Agric. 2020, 172, 105352, doi:https://doi.org/10.1016/j.compag.2020.105352.

39. Vishwakarma, D.K.; Pandey, K.; Kaur, A.; Kushwaha, N.L.; Kumar, R.; Ali, R.; Elbeltagi, A.; Kuriqi, A. Methods to estimate evapotranspiration in humid and subtropical climate conditions. Agric. Water Manag. 2022, 261, 107378, doi:https://doi.org/10.1016/j.agwat.2021.107378. 
40. Singh, V.K.; Kumar, D.; Kashyap, P.S.; Singh, P.K.; Kumar, A.; Singh, S.K. Modelling of soil permeability using different data driven algorithms based on physical properties of soil. J. Hydrol. 2020, 580, 124223, doi:https://doi.org/10.1016/j.jhydrol.2019.124223.

41. Moriasi, D.N.; Gitau, M.W.; Pai, N.; Daggupati, P. Hydrologic and water quality models: Performance measures and evaluation criteria. Trans. ASABE 2015, 58, 1763-1785, doi:doi: 10.13031/trans.58.10715.

42. Stamenković, L.J. Application of ANN and SVM for prediction nutrients in rivers. J. Environ. Sci. Heal. Part A 2021, 56, 867873, doi:10.1080/10934529.2021.1933325.

43. Rahgoshay, M.; Feiznia, S.; Arian, M.; Hashemi, S.A.A. Modeling daily suspended sediment load using improved support vector machine model and genetic algorithm. Environ. Sci. Pollut. Res. 2018, 25, 35693-35706, doi:10.1007/s11356-018-3533-6.

44. Massah, J.; Vakilian, K.A.; Shabanian, M.; Shariatmadari, S.M. Design, development, and performance evaluation of a robot for yield estimation of kiwifruit. Comput. Electron. Agric. 2021, 185, 106132, doi:https://doi.org/10.1016/j.compag.2021.106132. 